\title{
HELIANT HEALTH INFORMATION SYSTEM AS A SUPPORT TO ELECTRONIC BUSINESS OF HEALTHCARE ORGANIZATIONS IN SERBIA

\author{
UDC 004:614.2(497.11)
}

\author{
Žarko Rađenović*, Slavoljub Milovanović, Goran Milovanović \\ University of Niš, Faculty of Economics, Niš, Serbia
}

\begin{abstract}
Electronic business of healthcare organizations is a specific technological innovation when it comes to providing adequate healthcare services. The process of providing healthcare services in this case is supported by electronic health record, which is an integral part of health information systems. Monitoring of the healthcare services providing process using tools of electronic health (e-health) in this paper, will be based on the software for graphical modelling, which will target key activities, participants and variables of the process, and make its mapping. This is because the analysis of electronic business processes of healthcare organizations reveals activities that can be cost-optimized for more efficient delivery of health services and faster response on the patient's condition. In this work, process analysis was conducted on the case of health information system Heliant Health, which is used in most public medical institutions of the Republic of Serbia.
\end{abstract}

Key words: electronic business, electronic health, electronic health record, process analysis, healthcare organizations

JEL Classification: C63, I10, M15, P36

\section{INTRODUCTION}

Research motivation for writing this paper is the problem of implementation, use and development of integrated health information systems in the Republic of Serbia. A special attention in this paper relates to Heliant Health, a health information system that is used in local healthcare centers, hospitals and most clinics on the territory of the Republic of

Received March 8, 2017 / Revised May 02, 2017/ Revised June 23, 2017 / Accepted July 05, 2017

Corresponding author: Žarko Rađenović, ${ }^{*}$ PhD student at Faculty of Economics Niš

University of Niš, Faculty of Economics, Trg kralja Aleksandra 11, Serbia

E-mail: zarkoradjenovic2@gmail.com 
Serbia. Its functioning will be analyzed in the light of compatibility with the International standard for health information systems Health Level Seven- HL7, which provides basic guidelines for networking, communication and monitoring of the patient health condition, by all participants in the process of providing healthcare services, at the primary, secondary and tertiary level.

One of the major research problems in this paper is analyzing the efficiency and interoperability of business processes, providing healthcare services. Using one of the most popular norms of graphic process modelling Business Process Modelling Notation 2.0 (BPMN 2.0), with the addition of a Gantt chart of all electronic activities providing healthcare services, we will analyze the functioning of the health information system (HIS) Heliant Health, used in the Republic of Serbia and its comparison with the HL7 concept. Also, this paper deals with the analysis of the medical treatments at all levels of healthcare protection which is supported by electronic health record information as an important tool in the patient's treatment. All of this aims to detect any distortion in the execution of the healthcare organizations business processes, and make recommendations for improvement and increasing efficiency in patient treatment, a better integration of health stuff and save time and resources providing healthcare services.

One of the key problems related to Heliant Health, in the context of the standard HL7, is primarily the absence of network and disconnection of some of the participants in the process of providing healthcare services using electronic health records, which leads to delays in treatment and effective monitoring of the patient and timely response in case of urgent situations. The connection between participants in the process of providing healthcare at the primary, secondary and tertiary levels can be achieved by adjusting the Heliant Health process to HL7 standards. Also, it is possible to implement changes to improve the process of providing healthcare services through the Health Heliant, in order to achieve compatibility with the HL7 standards.

\section{Methodology AND LITERATURE REVIEW}

Research methodology in order to obtain the appropriate results and answers of setting hypothesis of the paper will be based on BPMN modelling. Specifically, using BPMN in this paper will be created the process of providing healthcare services at the primary, secondary and tertiary levels with the support of the electronic card based on the current situation in the Republic of Serbia, using Heliant Health health information System. Also, through the process modelling will be given a proposal for improving the provision of healthcare services. On the other hand, using a Gantt chart created on the basis of BPMN process, you should become familiar with the activities duration of providing healthcare services process and their percentage contribution to carry out the process of providing healthcare services supported by Heliant Health. On the basis of their (in)compatibility we will give proposals for improving the integration of the participants, in order to achieve the standard HL7 and provided even international cooperation in delivery of healthcare services, of course with the support of information from electronic medical record. In addition, the methodology used in this work will be explained in detail using BPMN tools. 
Electronic health as a growing research field in both the public and private health sector, as well as in e-business and IT, shows the importance of developing a serviceoriented architecture of information systems associated with web. This resulted in the number of papers that aim to analyze e-business models of healthcare organization and bridge the gap between theory and practice. In order to understanding business objectives of healthcare organizations in their work Alahmadi, Soh and Ullah, analyzed the entire flow of the providing healthcare services process and its main features (Alahmadi et al., 2014). On the other hand, the laying of foundations, both in literature and in practice with regard to the development of e-health in recent years placed Emanuele and Koetter discovering opportunities and challenges for further evolution of e-Health (Emanuele \& Koetter, 2007).

Business process modelling and its management, in order to decrease operational and other costs and also human errors, make a significant progress in case of analizing electronic health data and improving healthcare services (Becker, J. \& Janiesch, C., 2007). Also, using workflow methodology with software tools, Electronic Health Record systems and its features could be better monitored and controlled and contributes to more efficient e-business of healthcare organizations (Alhaqbani, B. \& Fidge, C., 2007).

\section{DefinING THE Model OF PRocess}

Successful organization management, and especially increasing its efficiency in order to achieve the goals set, is possible only under the assumption of excellent knowledge of its internal composition and mode of operation. Organizational operations are achieved through a series of related and goal oriented business processes. The complete definition of the business process in principle is never final, but it can be assumed that the business process is a set of related work steps for which it is possible to determine the duration and necessary resources.

The organization efficiency can be increased by improving and restructuring its business processes. However, it is essential that all participants fully understand the business processes, which will be possible if the processes are described in a unique and accessible way. Business processes and their connections may be described using various techniques. Description by spoken language is certainly one way, but it can be imprecise, and communication capabilities could expose participants to different interpretations of spoken words. So, today's business processes are accurately described by a set of graphical symbols with precisely defined semantics and firm rules of their connection.

Modeling business processes is achieved by effectively controlling the quality of business processes performances in line with the business strategy. If an organization sets a high-quality monitoring system of business process, modeling will provide long-term profit. Because of their dynamic presentation, simulation methods are now more attractive, so the software solutions, that are based on the graphic modelling, are increasingly integrated with the rolled programming language into executable language that can be displayed as a simulation. One of the most common graphic norms for modelling processes is BPMN 2.0 with the addition of the programming language execution (Rojo et al., 2010). 
Regardless of the modelling selection methods, it is necessary to know something about software solutions, which facilitate the business modelling, and not cause additional complications. It requires IT personnel to perform modelling in accordance with the needs of companies, which includes additional investments that the company was not always willing to implement, because the results appear only after a certain time. These are investments with indirect economic impacts, where exploitation occurs after a certain period of using the investment. This study and research paper deals with the analysis of the medical treatments at all levels of healthcare protection which is supported by electronic medical records, in order to answer the question of business processes efficiency of healthcare organizations, as a specific business entities.

According to the generic definition of the business process, it is a set of related activities and decisions, which is performed on external incentive to achieve a measurable objective of organization, takes time and consumes few resources as input, transforming them into specific products or services of interest to the customer or user. Analyzing the definitions in some detail by showing the following parts (Emanuele \& Koetter, 2007):

- A set of related activities and decisions. It means that this is a deliberate set of actions and decisions (and not a conglomerate) that lead to achieving the objectives and satisfying the needs of some customers or users.

- It runs on external incentive.

- The organization does nothing nor consumes any resources if there is no requirement or incentive from a customer or user. In manufacturing organizations that incentive is customer orders, even though it may not always be immediate, but it can be planned (depending on the system of production management).

- Specific products or services. Each output execution process must be individually identifiable (meaning that it cannot give any other process), and measurable. For example, Process Design and Development (this can be a group of processes, but also the name of the organizational unit that performs them) is not a process, instead of that the process will be designed transformer.

- Value for customer. Organization which exists in itself would have no sense, it only exists because of the customers or users of its products or services. However, in complex organizations whose activities are organized on the principle of the value chain (the Value Chain) customer or the user may not always be the external, but it may be some internal organizational units.

It should be noted that this definition of the business process should not be taken formally. Practice shows that a large effort around modelling is useless if at the beginning the processes that correspond to this definition are not recognized.

\section{THE Role OF ELECTRONIC HEALTH RECORD IN THE BUSINESS OF HEALTHCARE ORGANIZATIONS}

The electronic health record (EHR) of an individual user/patient is a set of longitudinal data (continuously throughout life) essential for health, collected and pulled from electronic medical histories, and electronic patient records from different healthcare institutions, which could be shared between relevant health institutions and/or healthcare professionals for the purpose of health promotion, disease prevention, diagnosis, treatment 
and rehabilitation of these patients. The main objective of the EHR establishment is to provide quality healthcare and increase overall efficiency, quality and safety of the system in order to provide benefits primarily for patients and healthcare workers accessing highquality data and provide information for the development strategy, better management and health policy. The purpose of the EHR is the integration of information systems of various medical institutions through the collection of personal data about health status of patients, and their electronic downloading from the place where services are provided. This enables better communication of health workers and awareness about relevant health information for a specific person, and therefore increases the possibility of successful treatment.

Implementation of information and communication technologies in healthcare systems is followed by the emergence of new terms and concepts and their use in different contexts, both in Serbia and in all the countries in the world and in all languages. Some of the most commonly used terms in Serbia are "electronic health record", "electronic medical history", "electronic health records", "electronic health record" and other terms that, at first sight, are the same. The second term represents a group of so-called "unified electronic health records" (Eng. "Electronic health record"), which includes all the information about patients that were recorded continuously throughout their lives. It also includes information about medical services that have occurred in various health institutions according to the current patient state.

The terms "electronic patient record" and "electronic medical histories of patients' indicate electronic records in healthcare organizations, analogous to writing (paper) documents, "cards" in primary healthcare and "medical histories" in hospitals. For this type of electronic records it is true that its emergence resulted from the introduction of ICT in individual institutions, and they are primarily used by the healthcare workers who have direct contact with patients in the healthcare service. They primarily serve for medical procedures or processes of health promotion, disease prevention, diagnosis, treatment and rehabilitation with individual customers/patients (possibly with a small group of users/patients).

Taking all of the above mentioned into account, in the context of healthcare system in Serbia, we can briefly say that "electronic patient record" (in the primary healthcare), or "electronic medical histories of patients" (in the secondary and tertiary healthcare) corresponds to the English term "electronic medical record - EMR" and contains information related to the work in individual practices of healthcare workers, or in a health institution or private practice (in accordance with the Law on healthcare in the Republic of Serbia). Compared to the medical records in written (paper) form, the electronic card and electronic medical history of the patient have the following advantages (Kirchner et al., 2013):

- Easy identification and monitoring of patients in time for preventative checks, inspections or screening,

- Easy monitoring of certain essential characteristics and findings in patient state, such as blood pressure, sugar levels in blood, immunization (vaccination), etc.,

- Easy monitoring and evaluation of their own practice, as well as conducive, data and evidence-based, planning and implementation of quality improvement and safety practices of health workers and institutions. 
What is crucial for electronic medical histories (electronic cards) of patients is a very limited flow of health information and data, and the data of patients (sometimes crucial for health) remain within the limits of a health institution. What typically happens when it is necessary to transmit information to other healthcare professionals is that the necessary information is usually printed and also in writing, transfers to other health institutions. In terms of exchange and flow of information between different medical institutions, electronic medical history (cardboard) of patients does not differ much from medical records in paper form.

\subsection{Process analysis of Heliant Health activities using BPMN}

The process analysis of Heliant Health activities was done in order to clearly target all the activities carried out during the e-health in one organization which is normally used by the mentioned health information system. Namely, it is evident that there is a medical procedure that must be respected and therefore e-commerce of healthcare organizations which provide healthcare services for patients (Kelley \& Hurst, 2006). Mapping the process of providing healthcare services electronically, in the case of cardio-vascular disease patients, clearly defines those activities that are essential for the smooth patient care and the sharing of information about their condition. Of course, sharing information is followed by electronic medical records data in Heliant Health, as has been said, is the basis for determining the therapy and diagnosis of the patient.

In order to clearly realize the possible "bottlenecks" in e-business of healthcare organizations and improve the efficiency and cost optimization, authors made a list of activities, their duration and the percentage contribution to the process execution for a hypothetical case of cardiovascular disease patients (Table 1). It is necessary to emphasize that activity duration was determined using examples of good practice, in case of Serbian healthcare services on primary, secondary and tertiary level of health protection, after some researches which are conducted by authors in Serbian healthcare organizations. The compressed types of activities within the business process model (there are thirty-one) of treating a patient with the electronic health records support are:

- Calling Call Centre in order to make appointments,

- Scheduling an appointment with their chosen doctor,

- Assessing the state of urgency by the chosen doctor,

- Examination by the chosen doctor,

- Referral to additional diagnostic methods,

- Receiving the patient due to the urgency state out of the ordinary procedure,

- Patient's hospitalization and their retention in the stationary treatment with possible further clinical intervention and consultative review. After that, it is possible to send the patient to a rehabilitation center or discharge after receiving treatment and return to the selected physician with the arrival of home healthcare and assistance,

- Setting up final diagnosis by the chosen doctor after interpretation of laboratory results and radiology results with the correction of existing therapies and determining the final therapies. 
Heliant Health Information System as a Support to Electronic Business of Healthcare Organizations in Serbia 271

Table 1 Activities and their duration in Heliant Health

\begin{tabular}{|c|c|c|c|c|c|}
\hline Activity name & $\begin{array}{l}\text { Sequence } \\
\text { of } \\
\text { activities }\end{array}$ & $\begin{array}{c}\text { Activity } \\
\text { beginning }\end{array}$ & $\begin{array}{l}\text { Activity duration } \\
\text { (in days) }\end{array}$ & $\begin{array}{l}\text { Cumulative } \\
\text { activity }\end{array}$ & $\begin{array}{c}\text { The percentage } \\
\text { share of activity in } \\
\text { the overall activities }\end{array}$ \\
\hline Calling the call center & - & $01 / 10 / 17$ & 1.00 & 1.00 & $0 \%$ \\
\hline $\begin{array}{l}\text { Appointments with the chosen } \\
\text { doctor }\end{array}$ & - & $01 / 10 / 17$ & 1.00 & 2.00 & $1 \%$ \\
\hline $\begin{array}{l}\text { Assessment of the patient urgency } \\
\text { state }\end{array}$ & $\mathrm{x} 1, \mathrm{x} 2$ & $01 / 11 / 017$ & 1.00 & 3.00 & $1 \%$ \\
\hline Examination by the chosen doctor & $\mathrm{x} 1, \mathrm{x} 2$ & $01 / 11 / 17$ & 1.00 & 4.00 & $1 \%$ \\
\hline $\begin{array}{l}\text { Referral to other diagnostic } \\
\text { methods }\end{array}$ & $\mathrm{x} 4$ & $01 / 13 / 17$ & 2.00 & 6.00 & $2 \%$ \\
\hline Laboratory & $\mathrm{x} 5$ & $01 / 15 / 17$ & 2.00 & 8.00 & $3 \%$ \\
\hline Radiology & $\mathrm{x} 5$ & $01 / 17 / 17$ & 2.00 & 10.00 & $3 \%$ \\
\hline $\begin{array}{l}\text { Emergency state and } \\
\text { hospitalization outside the } \\
\text { protocol }\end{array}$ & $\mathrm{x} 3$ & $01 / 18 / 17$ & 1.00 & 11.00 & $4 \%$ \\
\hline Hospitalization & $\mathrm{x} 8$ & $01 / 19 / 17$ & 1.00 & 12.00 & $4 \%$ \\
\hline Staying in hospital & x9 & $01 / 21 / 17$ & 3.00 & 15.00 & $5 \%$ \\
\hline Carrying out appropriate therapy & $\mathrm{x} 4, \mathrm{x} 10$ & $01 / 23 / 17$ & 2.00 & 17.00 & $6 \%$ \\
\hline Return to the chosen doctor & $\mathrm{x} 11$ & $01 / 24 / 17$ & 1.00 & 18.00 & $6 \%$ \\
\hline $\begin{array}{l}\text { Finally diagnosis by the chosen } \\
\text { doctor }\end{array}$ & $\mathrm{x} 11, \mathrm{x} 12$ & $01 / 19 / 17$ & 1.00 & 19.00 & $7 \%$ \\
\hline $\begin{array}{l}\text { Other analyses in Institute of } \\
\text { Public Health }\end{array}$ & $\mathrm{x} 5$ & $01 / 17 / 17$ & 2.00 & 21.00 & $7 \%$ \\
\hline Results interpretation & $\mathrm{x} 14$ & $01 / 18 / 17$ & 1.00 & 22.00 & $8 \%$ \\
\hline $\begin{array}{l}\text { Ending of examination and giving } \\
\text { final therapy }\end{array}$ & $\mathrm{x} 15$ & $01 / 20 / 17$ & 2.00 & 24.00 & $8 \%$ \\
\hline Determining last and final therapy & $\mathrm{x} 16, \mathrm{x} 4$ & $01 / 21 / 17$ & 1.00 & 25.00 & $9 \%$ \\
\hline $\begin{array}{l}\text { Referral of the patient to a } \\
\text { specialist }\end{array}$ & x14 & $01 / 19 / 17$ & 2.00 & 27.00 & $9 \%$ \\
\hline Examination by the specialist & $\mathrm{x} 18$ & $01 / 20 / 17$ & 1.00 & 28.00 & $10 \%$ \\
\hline Final diagnosis by the specialist & $\mathrm{x} 19$ & $01 / 21 / 17$ & 1.00 & 29.00 & $10 \%$ \\
\hline Inpatient treatment & $\mathrm{x} 19$ & $01 / 23 / 17$ & 2.00 & 31.00 & $11 \%$ \\
\hline $\begin{array}{l}\text { Implementation of the inpatient } \\
\text { treatment }\end{array}$ & $\mathrm{x} 21$ & $01 / 29 / 17$ & 7.00 & 38.00 & $13 \%$ \\
\hline $\begin{array}{l}\text { Leaving the hospitalization } \\
\text { process }\end{array}$ & $\mathrm{x} 22$ & $02 / 07 / 17$ & 10.00 & 48.00 & $17 \%$ \\
\hline $\begin{array}{l}\text { Approval of the medical } \\
\text { commission for treatment at } \\
\text { tertiary level }\end{array}$ & $\mathrm{x} 22$ & $02 / 11 / 17$ & 15.00 & 63.00 & $22 \%$ \\
\hline $\begin{array}{l}\text { Performing conciliar examination } \\
\text { at the clinic }\end{array}$ & $\mathrm{x} 24$ & $02 / 20 / 17$ & 10.00 & 73.00 & $25 \%$ \\
\hline $\begin{array}{l}\text { The implementation of treatment } \\
\text { at the clinic }\end{array}$ & $\mathrm{x} 25$ & $04 / 19 / 17$ & 60.00 & 133.00 & $46 \%$ \\
\hline $\begin{array}{l}\text { Carrying out additional } \\
\text { examination and appropriate } \\
\text { therapy }\end{array}$ & $\mathrm{x} 26$ & $04 / 25 / 17$ & 7.00 & 140.00 & $48 \%$ \\
\hline Referral to the rehabilitation center & $\mathrm{x} 27$ & $07 / 24 / 17$ & 90.00 & 230.00 & $79 \%$ \\
\hline $\begin{array}{l}\text { Activation of the department of } \\
\text { home care after the completion of } \\
\text { the intervention }\end{array}$ & $\mathrm{x} 27$ & $06 / 24 / 17$ & 60.00 & 290.00 & $97 \%$ \\
\hline $\begin{array}{l}\text { Return to the selected physician } \\
\text { for further follow-up }\end{array}$ & $\mathrm{x} 27$ & $05 / 02 / 17$ & 8.00 & 298.00 & $100 \%$ \\
\hline
\end{tabular}


To make the process of e-business health organizations supported by Heliant Health successful, it is necessary to map the current processes and activities and establish a clear categorization of participants in the process and its variables. The participants in the process of electronic healthcare services, supported by Heliant Health are: patient, nurse, attending physician (chosen doctor), specialist, laboratory, radiology, Department of Public Health, medical board (Commission), clinic, hospital, rehabilitation center, home healthcare (nursing at home). In this case the process variables of electronic healthcare services are informational units, which define and determine the direction of unwinding activity based on their type. The variables of Heliant Health in treating a patient from primary to tertiary healthcare, supported by electronic medical records, in case of a cardio-vascular disease include:

- Code of electronic health record- type String.

- Patient name- type String.

- Laboratory results- type Integer: this results are usually in number format such as level of cholesterol, number of blood cells, level of diabetes etc.

- Radiology results- type String.

- Assessment of medical commission- type String.

- Results after the intervention- type String.

- The urgency states- type Boolean: authors choose Boolean type for this variable because the state may be or maybe not be urgent, depending on the patient health condition at a specific moment.

- Working diagnosis- type String.

- Work therapy- type String.

- The final diagnosis- type String.

- The final therapy- type String.

- Discharge list- type String.

The following section (Figure 1) gives a graphical representation of the existing business processes of the patient treatment with the electronic health record support. Before the presentation obtained by the process (before and after improvements), it is necessary to emphasize that this study respected all the principles in describing and graphical representation of the process through a BPMN (Rojo et al., 2010):

- The principle of abstraction - a better understanding of the problem, it must be presented in a simplified form. The problem should be separated from the real environment and the background details which diminish its complexity should be ignored.

- The principle of formality - provides a methodical approach to the problem according to appropriate procedures. It introduces algorithms, rules and laws.

- The principle of modularity - the problem is divided into less complex parts, modules in order to understand them better.

- The principle of hierarchy - the problem is also divided into modules, which are classified according to their complexity, from the simplest to the most complex. 
Heliant Health Information System as a Support to Electronic Business of Healthcare Organizations in Serbia 273

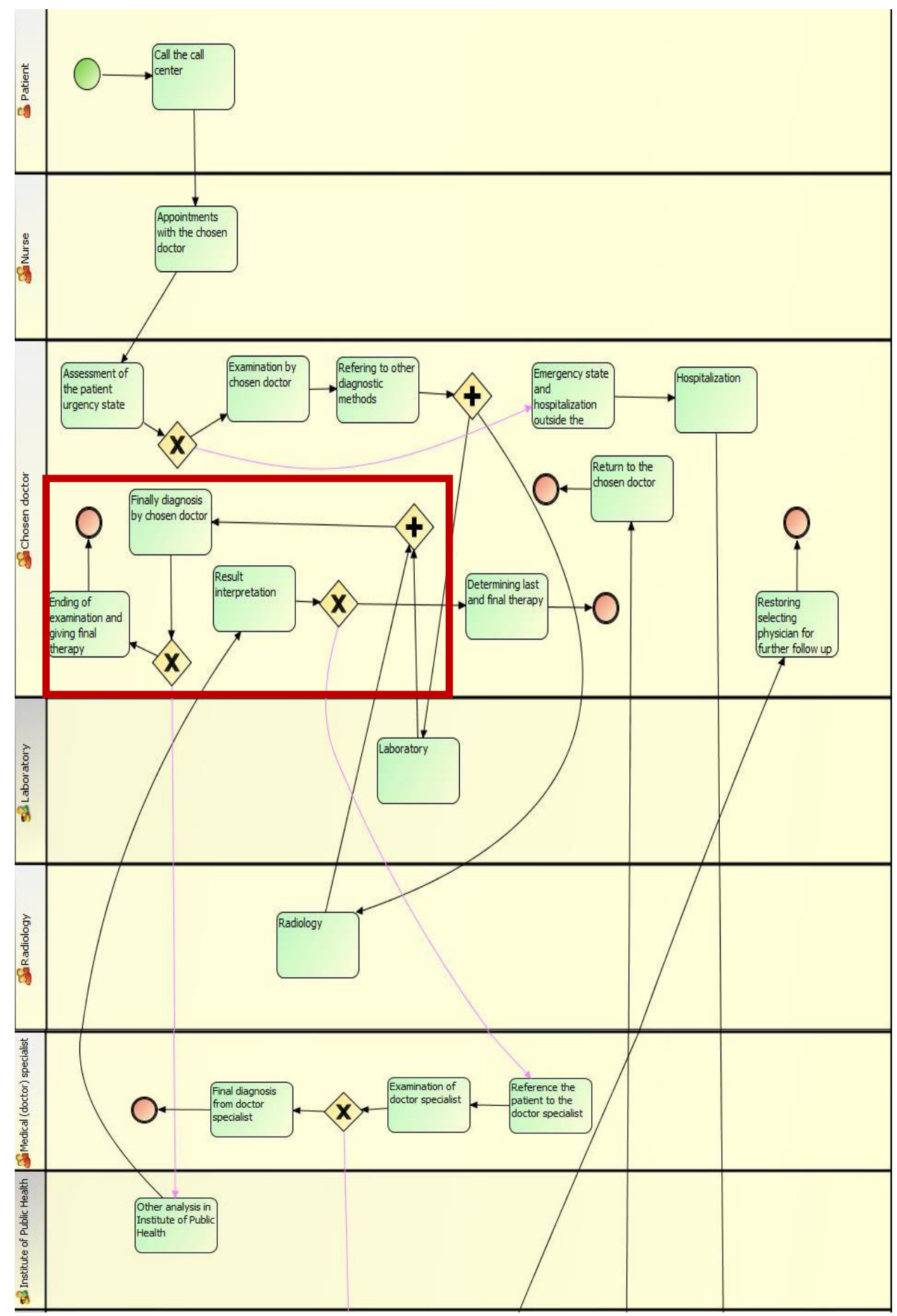




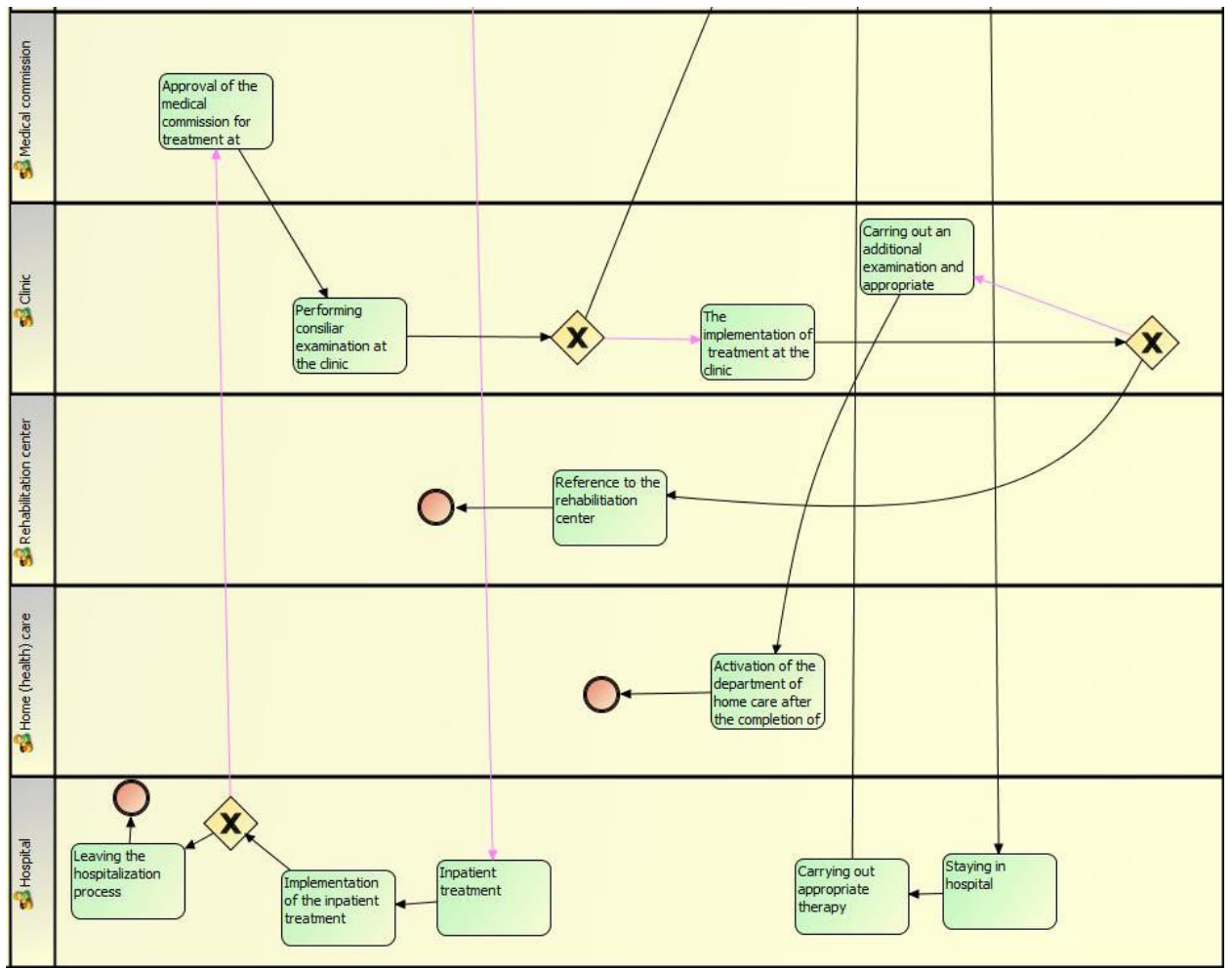

Fig. 1 Current process of providing healthcare services supported by Heliant Health Source: Authors

After mapping the process of providing healthcare services supported by electronic health record of Heliant Health Information System, using BPMN, we composed Gantt chart based on Table 1 showing:

- Name (type) of activity which is provided by healthcare services through health information system.

- The order in which activities take place and their relationship.

- Duration of activities and their potential overlapping.

- Cumulative realization showing the sum of the duration of these activities and the activities which follow.

- The percentage share of each activity in the provision of healthcare services through the Heliant Health.

Gantt chart is the graphical display (Figure 2), based on Table 1 which documented current activities and their possible overlap in terms of the interdependence of these activities, as it has been seen which activities are "bottlenecks" of the process of providing healthcare services. Specifically, the duration of each activity is perceived in this way and the way it "slows down" and "accelerates" the process of providing healthcare services using electronic medical records. This could reveal key activities, which could be merged into a larger activity, or completely eliminated from the process of providing healthcare services by 
Heliant Health, in order to avoid decreased efficiency and interoperability of organization ehealth.

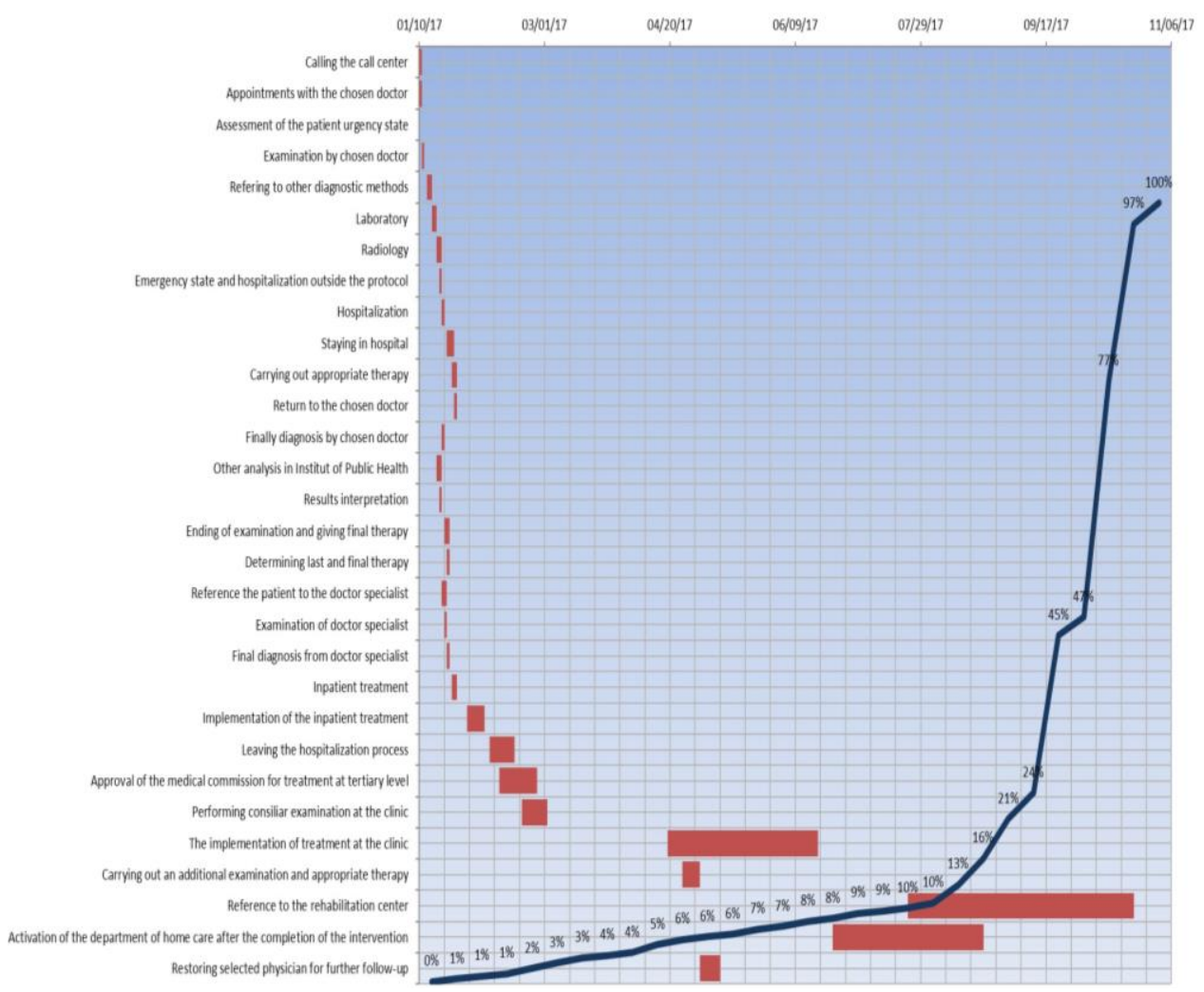

Fig. 2 Gantt chart of activities in Heliant Health Source: Authors

\subsection{Suggestions for electronic business processes improvement supported by Heliant Health}

The enhanced version of the treatment process at all levels of healthcare (Figure 3), supported by electronic health record, which indicates the potential drawbacks of the existing business processes, provides a graphical representation of the parts of improved processes or activities. The improvement of the performances of those activities, which lead to delays in the provision of healthcare services, comes to higher efficiency and interoperability of healthcare organizations. This version shows an improved process in which part of the patient treatment at all levels should remove the shortcomings. Namely, according to the research, it proposed improvement treatment process in the following areas:

- Setting the final diagnosis.

- Determination of the results obtained after the treatment.

- Interpretation of laboratory results and other. 
The treatment process at all levels of healthcare (primary, secondary and tertiary) supported by the electronic health record increases the efficiency of healthcare organizations by:

- Reducing administrative costs, operating costs and the costs of treatment.

- Reducing the number of required operations in the case of intervention due to the deteriorating health condition of the patient and allowing the provision of adequate and timely therapy.

- Allowing a better insight into the history of the disease and better interaction between the chosen doctor and the patient.

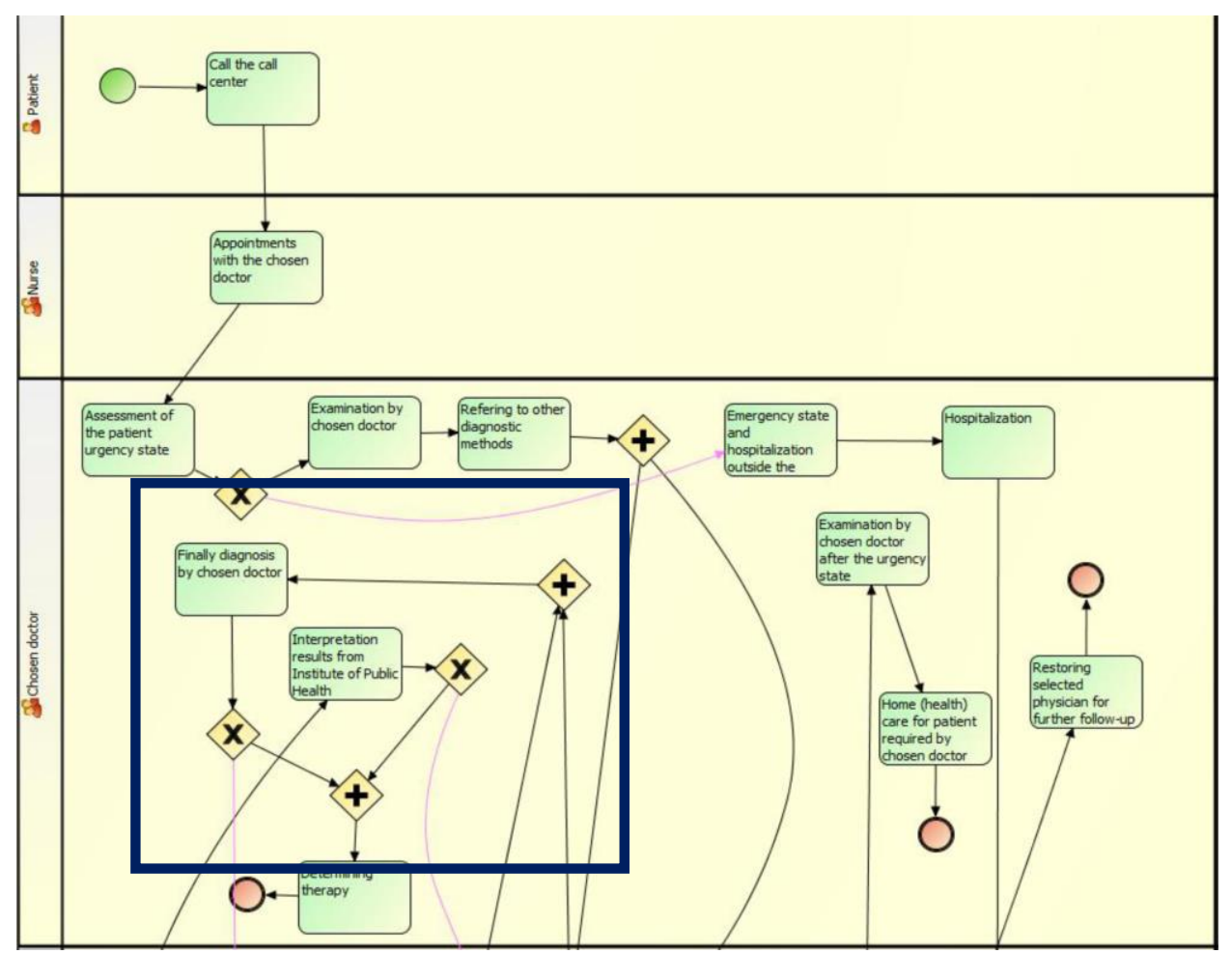

Fig. 3 Suggestions for improving the current process of healthcare services in Heliant Health Source: Authors

The processes of development and implementation of electronic health records have a long-term strategic significance. Once it reaches the full functionality, most health organizations and health workers and most of the population of healthcare will be included in the system of electronic health records. It provides primarily the availability of relevant and up-to-date health information to all stakeholders (Emanuele \& Koetter, 2007). The benefits of the proposed improvement of health information system Heliant Health, supported by electronic medical records, may be the following:

- Health information system based on electronic medical records such as Heliant Health brings benefits in time savings. Namely, healthcare stakeholders could schedule their 
own appointments with healthcare staff in some healthcare organization. Also, patients could arrange an on-line consultation using a video link.

- Patients could make a personal healthcare environment which gives them the possibility to share their own medical data with the healthcare provider. It gives them more control over their health condition, but also makes medical staff more efficient in case of faster determining the right treatment in real-time without mistakes.

- Medical staff could share information more securely with colleagues and less paperwork allows them to spend more time and pay more attention to patients' condition and needs.

- Using reliable, high-quality, protected, comprehensive and easily accessible healthcare data brings better quality and safety of healthcare services (healthcare intelligence), management (management intelligence), reporting and evaluation in the health system (public health intelligence), business (business intelligence).

\section{CONCLUSION}

The development of information systems and the growing trends in the industry of information technology have enabled their use in health organizations in order to increase the provision of healthcare services. During the development and implementation of information systems to support electronic healthcare is extremely important in order to choose the best alternative among the many that exist in the market. The correct choice of a health information system with respect to standards such as the HL 7 will provide not only the cost and operational efficiency, but also better communication among healthcare organizational units and a higher degree of interoperability, collaboration and coordination. In this way, information systems (with the multi-stakeholder approach) in healthcare organizations provide a higher level of services quality resulting from adequately collected and analyzed information of the patients' health status.

These principles are based on guidelines and concepts of the HL7 standard which also reflect its character. Improving Heliant Health should be based on the recommendations of this standard to maximize the integration and interoperability of healthcare organizations. Consequently, it can be said that based on research, compatibility between Heliant Health and the HL7 standard, using BPMN, and confirmation of the hypotheses and their validity, is proved. In this way, recommendations for process improvement in modelling are given, as well as guidelines for further integration of the participants through electronic health records, especially in communication between institutions and health personnel of primary and secondary healthcare.

Contribution to the improvement of existing provision of healthcare services supported by electronic medical records, based on previously conducted research, is reflected in reduction of administrative work and cost accounting. Also, workflow methodology gives proposals for avoiding unsafe and unnecessary interventions and a faster reaction to some urgency states, using adequate therapy, by targeting inefficient activities of healthcare services. This new generation of information-intensive telemedicine services, with its innovative high-tech tools, embodied in health information systems, causes the setting up of health services to a higher evolutionary level, especially in terms of efficiency.

The cost and qualitative components of health services achieve an enviable level of performance when it comes to electronic healthcare. On the other hand, the timely exchange of information in the virtual mode allows adequate treatment of the patient's disease, 
without a time delay. In this way, the costs of introducing digitization into a health organization (based on example of good practice) can be reduced to only $3 \%$ of the total cost. The adaptability of users of health information systems has been enhanced by continuous education and the development of skills and competencies for using electronic health software solutions. This way, e-health improves the safety of all participants in the process of providing health services, but also increases the precision in the healthcare decision-making process, using workflow methodology. Improving the interoperability of a health organization and mobility of its members, using telemedicine services through an electronic health card leads to the strengthening of the stakeholders' functional networking inside the health organization.

Consequently, through these workflow software tools, the focus is on long-term economic, and above all the health benefits of using some of the software alternatives. It mainly aims at high personalization, customization and patient-orientation of the electronic health business solutions. On the other hand, the structure of a concrete health organization defines the utilization of software solutions for the implementation of the e-Health concept. Functional and evolutionary-minded hardware and software applicative infrastructure contributes to the consistency of the e-health concept, which provides all users of the system with a "user friendly" attitude towards software solution, which ultimately leads to the provision of timely and quick medical services in real time. In this way, by selecting the appropriate software solution, the health organization makes opportunity for better healthcare, collects and analyzes large amounts of information and monitors patients' medical histories.

\section{REFERENCES}

Alahmadi, A.H., Soh, B. \& Ullah, A. (2014). Improving of e- Health Services and System Requirements by Modelling the Health Environment. Journal of Software, 9 (5), 57-71.

Alhaqbani, B. \& Fidge, C. (2007). Access Control Requirements for Processing Electronic Health Records. In: The Fifth International Conference on Business Process Management: Enabling Change and Innovation. Workshop on BPM in Healthcare. (pp. 53- 65). Brisbane: Queensland University of Technology.

Becker, J. \& Janiesch, C. (2007). Restrictions in Process Design: A Case Study on Workflows in Healthcare. In: The Fifth International Conference on Business Process Management: Enabling Change and Innovation. Workshop on BPM in Healthcare. (pp. 5- 17). Brisbane: Queensland University of Technology.

CIDA (1997). Guide to gender-sensitive indicators. Ministry of Public Works and Government Services Canada

Dwivedi, A., Bali, R., James, A., \& Naguib, R. (2001). Work flow management systems: the healthcare technology of the future? In the 23rd Annual International Conference of the IEEE Engineering in Medicine and Biology Society. (pp. 3887-3890).

EC (2012). Proposal for a Regulation of the European Parliament and of the Council on the protection of individuals with regards to the processing of personal data and on the free movement of such data. EC: General Data Protection regulation.

El-Hassan, O., Fiadeiro, J.L. \& Heckel, R. (2007). Managing Socio-Technical Interactions in Healthcare Systems. In: The Fifth International Conference on Business Process Management: Enabling Change and Innovation. Workshop on BPM in Healthcare. (pp. 29- 41). Brisbane: Queensland University of Technology.

Emanuele, J. \& Koetter, L. (2007). Workflow Opportunities and Challenges in Healthcare. In: Fischer, L. (Eds.), BPM \& Workflow Handbook (pp. 157-166). Florida: Future Strategies Inc.

EPSOS (2012). Final definition of functional services requirements - Patient Summary. European Patient Smart Open Services

Esterle, L. \& Mathieu- Fritz, A. (2013). Teleconsultation in geriatrics: impact on professional practice. International Journal of Medical Informatics, 82 (8), 684- 695. 
Euro Health Group (2005). Konceptualno modeliranje - Koncept sistema EZD. (Conceptual ModellingConcept System EHR) Projekat: Razvoj zdravstvenog informacionog sistema za osnovne zdravstvene i farmaceutske usluge.

Kelley, E. \& J. Hurst (2006). Healthcare Quality Indicators Project: Conceptual Framework Paper. OECD Health Network Papers, 23, Paris: OECD Publishing. DOI: 10.1787/440134737301.

Kirchner, K., Malessa, Ch., Herzberg, N., Krumnow, S., Habrecht, O., Scheuerlein, H., Bauschke, A. \& Settmacher, U. (2013). Supporting liver transplantation by clinical pathway intelligence. Transplant Proc., 1981-2.

Mulyar, N., Pesic, M, Van der Aalst, W.M.P. \& Peleg, M. (2007). Declarative and Procedural Approaches for Modelling Clinical Guidelines. In: The Fifth International Conference on Business Process Management: Enabling Change and Innovation. Workshop on BPM in Healthcare. (pp. 17-29). Brisbane: Queensland University of Technology.

Mursaleena, I. (Eds.) (2007). Health Systems Assessment Approach: A How-To Manual. Arlington: U.S. Agency for International Development.

NHS (2011). The care record guarantee. Our guarantee for NHS care records in England. National Health Service (NHS) in England.

NIGB (2011). Access to Health Records by Diagnostic Staff: Guidance for Patients and Healthcare Professionals. National Information Governance Board (NIGB) for Health and Social Care.

Rojo, MC., Calahorra, L. \& Ruiz, F. (2010). BPMN in practice: Experiences of business modeling in the department of pathology. Diagnostic Pathology, 43-47. DOI:10.3233/978-1-61499-432-9-43.

Van Hee, K., Schonenberg, H., Serebrenik, A., Sidorova, N. \& Van der Werf, J.M (2007). Adaptive Workflows for Healthcare Information Systems. In: The Fifth International Conference on Business Process Management: Enabling Change and Innovation. Workshop on BPM in Healthcare. (pp. 41- 53). Brisbane: Queensland University of Technology.

\section{INFORMACIONI SISTEM HELIANT HEALTH KAO PODRŠKA ELEKTRONSKOM POSLOVANJU ZDRAVSTVENIH ORGANIZACIJA U SRBIJI}

Elektronsko poslovanje zdravstvenih organizacija predstavlja svojevrsnu tehnološku inovaciju kada je u pitanju adekvatno pružanje usluge zdravstvene zaštite. Proces pružanja usluga zdravstvene zaštite $u$ ovom slučaju podržan je elektronskim zdravstvenim kartonom, koji predstavlja integralni deo zdravstvenih informacionih sistema. Praćenje toka procesa pružanja zdravstvene usluge korišćenjem alata elektronskog zdravstva (e-health) u ovom radu, baziraće se na primeni softvera za grafičko modeliranje koji će targetirati ključne aktivnosti, učesnike $i$ varijable datog procesa, $i$ izvršiti njegovo mapiranje. Ovo zbog toga što se analizom procesa elektronskog poslovanja zdravstvenih organizacija otkrivaju one aktivnosti koje se mogu troškovno optimizovati u cilju efikasnijeg pružanja zdravstvene usluge i brže reakcije na stanje pacijenta. $U$ ovom radu procesna analiza sprovedena je na primeru zdravstvenog informacionog sistemaHeliant Health, koji se primenjuje u većini zdravstvenih ustanova javnog sektora Republike Srbije.

Ključne reči: elektronsko poslovanje, elektronsko zdravstvo, elektronski zdravstveni karton, procesna analiza, zdravstvene organizacije 